\title{
Knowledge, attitude and practice about hypertension in hypertensive patients attending hospitals in Baghdad, Iraq
}

\author{
Raghdaa Sadeq ${ }^{1}$, Riyadh K Lafta ${ }^{2}$
}

${ }^{1}$ Public Health Physician, Ministry of Health, Baghdad, Iraq. ${ }^{2}$ Professor, College of Medicine, Mustansiriya University, Baghdad, Iraq.

\begin{abstract}
Patients' knowledge and attitudes have an impact on the management of their illnesses. Obtaining information about the level of awareness is the first step in formulating a preventive program for any health problem. The aim of this study is to assess the knowledge, attitude and practice of hypertensive patients about their disease. A consecutive nonprobability sampling technique was adopted to collect all adult hypertensive patients that attended the outpatient clinic of the main three teaching hospitals in Baghdad city. Adults of both gender who had history of hypertension for at least six months were included in the study. A questionnaire was developed to assess the knowledge, attitude and practice of those patients. More than $60 \%$ had good knowledge, $80 \%$ expressed good attitude while $24 \%$ recorded good practice. Analyses of data revealed that the score of knowledge is significantly associated with age $(p=0.002)$ and gender $(p=0.002)$. It was also directly related to the education level. $(p=0.0001)$, duration of hypertension $(p=0.041)$ and the presence of positive family history of the disease $(p=0.0001)$. The attitude was significantly associated with age $(p=0.046)$, level of education $(p=0.008)$ and family history $(p=0.006)$. The score of practice was significantly associated with age $(p=.0008)$, and duration of hypertension $(p=0.004)$. Hypertensive patients in our community have relatively good knowledge and attitude, but poor practice and compliance to treatment. Efforts are needed to increase the awareness through continuous health education in the health facilities and health promotional programs via the mass media.
\end{abstract}

Keywords: Knowledge, attitude, practice, hypertension, Iraq.

\section{Introduction}

Hypertension is a common health problem worldwide with estimates as much as one billion patients, and cause of 7.1 million (one-third) of global preventable premature deaths. $^{1-4}$ It is one of the important reasons to visit the physicians in both developed and developing countries. It is estimated that hypertension is responsible for $62 \%$ of cerebrovascular diseases and $49 \%$ of ischemic heart diseases, ${ }^{5-7}$ and can be a significant cause of mortality due to coronary artery disease, stroke, and renal failure. ${ }^{8}$ It is a public health problem especially in the developing countries that are in a state of epidemiological transition from communicable to chronic non communicable diseases. ${ }^{9}$ Although it is a preventable and treatable disease, yet, without treatment it can lead to serious and life threatening complications. ${ }^{10}$

Hypertension is considered as the sixth leading cause of death in Iraq with a prevalence that ranges from $35.6 \%$ to $40 \%,{ }^{11}$ and a total number of 6535 deaths occurred during 2015. ${ }^{12}$ This prevalence may exceed $60 \%$ in diabetic patients. $^{13-14}$

There is no doubt that knowledge and attitudes of patients have an impact on the management of their illness, as they can influence compliance, hypertension control, morbidity and mortality of the patients. ${ }^{15}$ Obtaining information about the level of awareness from the general public and patients is the first step in formulating a preventive program for the disease. KAP surveys are effective in providing a baseline for evaluating

\section{Practice Points}

- Outbreak of rubella increased along with measles outbreak.

- Hypertension is a global public health problem especially in the developing countries which are in a state of epidemiological transition from communicable to chronic non communicable diseases.

- Obtaining information from the patients about the level of awareness is the first step in formulating a preventive program for the disease. KAP surveys are effective in providing a baseline data for evaluating intervention programs.

- The hypertensive patients in our community have relatively good knowledge and attitude but poor practice of hypertension, and low compliance to treatment.

- The current study revealed that the score of knowledge is significantly association with age, gender, educational level, duration of hypertension and the presence of positive family history of hypertension.

intervention programs. ${ }^{16}$ The objective of this study is to assess the knowledge, attitude and practice of hypertensive patients about their disease attending hospitals at Baghdad city, Iraq.

Correspondence: Dr. Raghdaa Sadeq, Public Health Physician, Ministry of Health, Baghdad, Iraq. E-mail: drraghdaasadeq@yahoo.com. 


\section{Materials and methods}

This cross-sectional study was conducted during the period from July to August 2016 in three teaching hospitals (Baghdad Medical City, Al-Yermouk, and Al-Kindy Teaching Hospitals). A consecutive nonprobability sampling technique was adopted to collect information from all the hypertensive patients attended the outpatient clinics of those teaching hospitals during the study period. Those three hospitals cover about onethird of the population of Baghdad city and represent both districts of Baghdad (Karkh and Russafa).

All adults (age more than 18 years) of both genders who have had hypertension for at least six months were included in the study. Patients who were not fully alert (for any reason) or those who had psychological problems were excluded.

A structured questionnaire was developed by the researchers and validated by the Scientific Committee of the Ministry of Health and Medical College/ Mustansiriya University. The questionnaire consisted of the following categories:

- Demographic characteristics of the patients: age, gender, occupation, level of education, family history and duration of having high blood pressure.

- Knowledge: the second part (ten questions) enquired about information related to hypertension e.g normal and abnormal blood pressure, predisposing factors, symptoms, complications, treatment, diet and prevention.

- $\quad$ Attitude and practice (ten questions for each): regular measuring of blood pressure and lipid profile, exercise, eating healthy food, consuming less salt, maintaining normal body weight, and compliance to treatment.

The data collection team consisted of six well trained health workers (three males and three females) with a good experience in the field, they were supervised by two family physicians. The team was subdivided in three groups, each included a male and female interviewer (to make dealing with patients of both genders more convenient), and each group of interviewers was assigned to collect information from patients in one of the three chosen teaching hospitals through the period of the data collection.

The questionnaire form was filled via a direct face to face interview. The interviewers first introduce themselves to the respondents, explaining to them the objective of the study and the questions that they are going to ask, giving them the full choice to participate and assuring them that all the information will be kept strictly confidential and will not be used for any purpose other than research work. The data collection was done on daily basis (excluding the weekends) for six consecutive weeks.

A simple traditional scoring was adopted by giving one mark for each correct answer in each part of the questionnaire (knowledge, attitude, and practice) and zero mark for each wrong answer. A total of four marks or less was considered to be "poor", five to seven marks was "fair" and a score of more than seven marks was considered as "good".

\section{Statistical analysis}

Data analysis was carried out using the available statistical program SPSS-22 (Statistical Package for Social Sciences- version 22). Data were presented in simple measures of frequency and percentage. The association was tested using Pearson Chi-square test $\left(\mathrm{x}^{2}\right.$ -test), and using Yate's correction or Fisher Exact test whenever applicable. Significance was considered with $\mathrm{p} \leq 0.05$.

\section{Results}

The respondents' age was range from 20 to 70 years, the majority was from 40-59 years age group which constituted about two-third of the sample $(64.4 \%)$. Both genders were almost equally distributed $(50.6 \%$ males vs. $49.4 \%$ females). More than half of the respondents (53\%) completed the secondary (or higher) schools, and $63.9 \%$ reported a family history of hypertension as shown in Table 1. It was also noted that the main source of information regarding hypertension gathered by the respondents was health workers $(87.3 \%)$ and the least was from medical journals and brochures $(1 \%)$.

Table 2 highlighted that $60.1 \%$ of the respondents had good knowledge, $80 \%$ expressed good attitude while only one-quarter $(24 \%)$ recorded good practice.

Table 1: Socio-demographic characteristics of the respondents

\begin{tabular}{|c|c|}
\hline Characteristics & Respondents (\%) \\
\hline \multicolumn{2}{|l|}{ Age (vears) } \\
\hline$<40$ & $71(12.1 \%)$ \\
\hline $40-49$ & $162(27.6 \%)$ \\
\hline $50-59$ & $216(36.8 \%)$ \\
\hline$>60$ & $138(23.5 \%)$ \\
\hline \multicolumn{2}{|l|}{ Gender } \\
\hline Male & $297(50.6 \%)$ \\
\hline Female & $290(49.4 \%)$ \\
\hline \multicolumn{2}{|l|}{ Education } \\
\hline Illiterate & $125(21.3 \%)$ \\
\hline Primary & $151(25.7 \%)$ \\
\hline Secondary & $233(39.7 \%)$ \\
\hline Higher Secondary & $78(13.3 \%)$ \\
\hline \multicolumn{2}{|c|}{ Duration of hypertension (year) } \\
\hline$<1$ & $52(8.9 \%)$ \\
\hline $1-5$ & $307(52.3 \%)$ \\
\hline$>5-10$ & $132(22.5 \%)$ \\
\hline$>10$ & $96(16.4 \%)$ \\
\hline \multicolumn{2}{|c|}{ Family history of hypertension } \\
\hline Positive & $375(63.9 \%)$ \\
\hline Negative & $212(36.1 \%)$ \\
\hline \multicolumn{2}{|l|}{ Source of information } \\
\hline Health workers & $512(87.2 \%)$ \\
\hline Relatives/friends & $58(9.9 \%)$ \\
\hline Media & $11(1.9 \%)$ \\
\hline Medical journals & $6(1.0 \%)$ \\
\hline
\end{tabular}

Table 2: KAP scores of the respondents

\begin{tabular}{|l|c|c|c|}
\hline \multirow{2}{*}{ KAP } & \multicolumn{3}{|c|}{$\begin{array}{c}\text { Respondents (\%) } \\
(\mathbf{n}=587)\end{array}$} \\
\cline { 2 - 4 } & Poor & Fair & Good \\
\hline Knowledge & $29(5 \%)$ & $205(34.9 \%)$ & $353(60.1 \%)$ \\
\hline Attitude & $1(0.2 \%)$ & $105(17.9 \%)$ & $481(81.9 \%)$ \\
\hline Practice & $13(2.2 \%)$ & $430(73.3 \%)$ & $144(24.5 \%)$ \\
\hline
\end{tabular}


Analyses of data revealed that there is a highly significant associations between the score of knowledge and age $(p=0.002)$ and gender $(p=0.002)$. It was also directly related to the level of education $(p=0.0001)$ and duration of hypertension $(p=0.041)$. The score of knowledge was also associated with the presence of positive family history of hypertension $(p=0.0001)$ as shown in Table 3 .

A statistically significant association was found between the score of attitude and age $(p=0.046)$, level of education $(p=0.008)$ and family history of hypertension $(p=0.006)$, while the association was insignificant regarding the gender and duration of hypertension (Table 4).

A significant association was also noted between the score of practice and age $(p=0.0008)$, and with duration of hypertension $(p=0.004)$, while no significant association was seen between practice and education, age, or family history of hypertension (Table 5).

\section{Discussion}

The key finding of the present study showed that majority of the hypertensive patients had good knowledge (60.1\%) and good attitude (81.9\%). This is comparable to a study conducted in Tanzania and showed that $66.8 \%$ of the respondents had good knowledge about hypertension. ${ }^{17}$

A KAP study in India among patients with hypertension and diabetes revealed that most of the respondents had good knowledge but poor attitude and practice toward the diseases. ${ }^{15}$ Another study in Ludhiana, India showed that the overall practices were not up to the mark. ${ }^{18}$ A study conducted in Jordan on 200 hypertensive patients attending primary health care centers suggested that most of the participants were knowledgeable and had positive attitudes towards hypertension. ${ }^{19}$

However, a number of studies ${ }^{20,21}$ showed that many hypertensive patients lack of appropriate knowledge about hypertension. Increasing the knowledge, awareness, and control of hypertension will reduce morbidity and mortality. The findings of other studies in Saudi Arabia, ${ }^{22}$ Nigeria, ${ }^{23}$ Ghana, ${ }^{24}$ and Pakistan ${ }^{25}$ indicated that there is a clear need for health education of hypertensive patients.

Table 3: Association of score of knowledge with some demographic factors

\begin{tabular}{|c|c|c|c|c|c|c|c|c|c|}
\hline \multirow{2}{*}{\multicolumn{2}{|c|}{ Variables }} & \multicolumn{8}{|c|}{ Respondents (\%) } \\
\hline & & & Poor & & Fair & & ood & Total & $\mathrm{X}^{2} ; P$ value \\
\hline \multirow[t]{4}{*}{ Age } & $<40$ & 6 & $(8.5 \%)$ & 28 & $(39.5 \%)$ & 37 & $52.0 \%)$ & 71 & \multirow{4}{*}{$\begin{array}{c}\mathrm{X} 2=20.71 ; \\
\text { d.f. }=6 ; p=0.002 *\end{array}$} \\
\hline & $40-49$ & 6 & $(3.7 \%)$ & 45 & $(27.8 \%)$ & 111 & $(68.5 \%)$ & 162 & \\
\hline & $50-59$ & 4 & $(2.0 \%)$ & 77 & $(35.5 \%)$ & 135 & $(62.5 \%)$ & 216 & \\
\hline & $60+$ & 13 & $(9.3 \%)$ & 55 & $(40.0 \%)$ & 70 & $(50.7 \%)$ & 138 & \\
\hline \multirow[t]{2}{*}{ Gender } & Male & 11 & $(3.7 \%)$ & 87 & $29.3 \%)$ & 199 & $(67.0 \%)$ & 297 & \multirow{2}{*}{$\begin{array}{c}\mathrm{X} 2=12.03 ; \\
\text { d.f. }=2 ; p=0.002\end{array}$} \\
\hline & Female & 18 & $(6.2 \%)$ & 118 & $(40.7 \%)$ & 154 & $(53.1 \%)$ & 290 & \\
\hline \multirow[t]{4}{*}{ Education } & Illiterate & 3 & $(10.4 \%)$ & 65 & $(52.0 \%)$ & 47 & $(37.6 \%)$ & 125 & \multirow{4}{*}{$\begin{array}{c}\mathrm{X} 2=52.44 ; \\
\text { d.f. }=6 ; \mathrm{P}<0.001 *\end{array}$} \\
\hline & Primary & 10 & $(6.6 \%)$ & 57 & $(37.7 \%)$ & 84 & $(55.7 \%)$ & 151 & \\
\hline & Secondary & 5 & $(2.2 \%)$ & 69 & $(29.6 \%)$ & 159 & $(68.2 \%)$ & 233 & \\
\hline & High & 1 & $(1.3 \%)$ & 14 & $(17.9 \%)$ & 63 & $(80.8 \%)$ & 78 & \\
\hline \multirow{4}{*}{$\begin{array}{l}\text { Duration of } \\
\text { Hypertension } \\
\text { (years) }\end{array}$} & $<1$ & 2 & $(3.9 \%)$ & 28 & $(53.8 \%)$ & 22 & $(42.3 \%)$ & 52 & \multirow{4}{*}{$\begin{array}{c}\mathrm{X} 2=13.16 ; \\
\text { d.f. }=6 ; p=0.041 *\end{array}$} \\
\hline & $1-5$ & 17 & $(5.5 \%)$ & 103 & $(33.5 \%)$ & 187 & $(61.0 \%)$ & 307 & \\
\hline & $>5-10$ & 3 & $(2.3 \%)$ & 41 & $(31.1 \%)$ & 88 & $(66.6 \%)$ & 132 & \\
\hline & $>10$ & 7 & $(7.3 \%)$ & 33 & $(34.3 \%)$ & 56 & $(58.4 \%)$ & 96 & \\
\hline \multirow{2}{*}{$\begin{array}{l}\text { Family history } \\
\text { of hypertension }\end{array}$} & Positive & 10 & $(2.7 \%)$ & 112 & $(29.9 \%)$ & 253 & $(67.4 \%)$ & 375 & \multirow{2}{*}{$\begin{array}{c}\mathrm{X} 2=27.75 ; \\
\text { d.f. }=2 ; p<0.001 *\end{array}$} \\
\hline & Negative & 19 & $(9.0 \%)$ & 93 & $(43.9 \%)$ & 100 & $(47.1 \%)$ & 212 & \\
\hline
\end{tabular}

Table 4: Association of score of attitude with some demographic factors

\begin{tabular}{|c|c|c|c|c|c|c|c|c|c|}
\hline \multirow{2}{*}{\multicolumn{2}{|c|}{ Variables }} & \multicolumn{8}{|c|}{ Respondents } \\
\hline & & \multicolumn{2}{|c|}{ Poor } & \multicolumn{2}{|r|}{ Fair } & \multicolumn{2}{|c|}{ Good } & \multirow{2}{*}{$\begin{array}{c}\text { Total } \\
71\end{array}$} & \multirow{5}{*}{$\begin{array}{c}\mathbf{X}^{2} ; \boldsymbol{P} \text { value } \dagger \\
\mathrm{X} 2=20.71 ; \\
\text { d.f. }=6 ; p=.002 *\end{array}$} \\
\hline \multirow[t]{4}{*}{ Age } & $<40$ & 0 & 0 & 9 & $(12.7 \%)$ & 62 & $87.3 \%)$ & & \\
\hline & $40-49$ & 1 & & 22 & $(13 / 6 \%)$ & 139 & $(86.0 \%)$ & 162 & \\
\hline & $50-59$ & 0 & 0 & 39 & $(18.0 \%)$ & 177 & $(82.0 \%)$ & 216 & \\
\hline & $60+$ & 0 & 0 & 35 & $(25.3 \%)$ & 103 & $(74.7 \%)$ & 138 & \\
\hline \multirow[t]{2}{*}{ Gender } & Male & 1 & & 52 & $(17.5 \%)$ & 244 & $(82.2 \%)$ & 297 & \multirow{2}{*}{$\begin{array}{c}\mathrm{X} 2=12.03 ; \\
\text { d.f. }=2 ; p=0.002\end{array}$} \\
\hline & Female & 0 & 0 & 53 & $(18.3 \%)$ & 237 & $(81.7 \%)$ & 290 & \\
\hline \multirow[t]{4}{*}{ Education } & Illiterate & 0 & 0 & 27 & $(21.6 \%)$ & 98 & $(78.4 \%)$ & 125 & \multirow{4}{*}{$\begin{array}{c}\mathrm{X} 2=52.44 ; \\
\text { d.f. }=6 ; \mathrm{P}<0.001 *\end{array}$} \\
\hline & Primary & 1 & & 33 & $(21.9 \%)$ & 117 & $(77.5 \%)$ & 151 & \\
\hline & Secondary & 0 & 0 & 41 & $(17.6 \%)$ & 192 & $(82.4 \%)$ & 233 & \\
\hline & High & 0 & 0 & 4 & $(5.1 \%)$ & 74 & $(94.9 \%)$ & 78 & \\
\hline \multirow{4}{*}{$\begin{array}{l}\text { Duration of hy- } \\
\text { pertension } \\
\text { (years) }\end{array}$} & $<1$ & 0 & 0 & 6 & $(11.5 \%)$ & 46 & $(88.5 \%)$ & 52 & \multirow{4}{*}{$\begin{array}{c}\mathrm{X} 2=13.16 ; \\
\text { d.f. }=6 ; p=0.041 *\end{array}$} \\
\hline & $1-5$ & 1 & & 56 & $(18.2 \%)$ & 250 & $(81.5 \%)$ & 307 & \\
\hline & $>5-10$ & 0 & 0 & 23 & $(9.9 \%)$ & 109 & $(90.1 \%)$ & 132 & \\
\hline & $>10$ & 0 & 0 & 20 & $(21.0 \%)$ & 76 & $(79.0 \%)$ & 96 & \\
\hline \multirow{2}{*}{$\begin{array}{l}\text { Family history } \\
\text { of hypertension }\end{array}$} & Positive & 1 & & 79 & $(21.1 \%)$ & 295 & $(78.7 \%)$ & 375 & \multirow{2}{*}{$\begin{array}{c}\mathrm{X} 2=27.75 ; \\
\text { d.f. }=2 ; p<0.001 *\end{array}$} \\
\hline & Negative & 0 & 0 & 26 & $(12.3 \%)$ & 186 & $(87.7 \%)$ & 212 & \\
\hline
\end{tabular}

$\dagger$ Test of significance done after re-categorization into Poor-Fair x Good

South East Asia Journal of Public Health 2017;7(1):29-34 
Table 5: Association of score of practice with some demographic factors

\begin{tabular}{|c|c|c|c|c|c|c|c|c|c|}
\hline & \multicolumn{8}{|c|}{ Respondents (\%) } \\
\hline & & \multicolumn{2}{|c|}{ Poor } & \multicolumn{2}{|r|}{ Fair } & \multicolumn{2}{|c|}{ Good } & Total & \multirow{5}{*}{$\begin{array}{c}\mathbf{X}^{2} ; \boldsymbol{P} \text { value } \dagger \\
\mathrm{X} 2=20.71 ; \\
\text { d.f. }=6 ; p=.002 *\end{array}$} \\
\hline \multirow[t]{4}{*}{ Age } & $<40$ & 7 & $(9.9 \%)$ & 48 & $(67.6 \%)$ & 16 & $(22.5 \%)$ & 71 & \\
\hline & $40-49$ & 3 & $(1.9 \%)$ & 116 & $(71.6 \%)$ & 43 & $(26.5 \%)$ & 162 & \\
\hline & $50-59$ & 2 & $(1.0 \%)$ & 161 & $(74.5 \%)$ & 53 & $(24.5 \%)$ & 216 & \\
\hline & $60+$ & 1 & $(0.7 \%)$ & 105 & $(76.1 \%)$ & 32 & $(23.2 \%)$ & 138 & \\
\hline \multirow[t]{2}{*}{ Gender } & Male & 8 & $(2.0 \%)$ & 218 & $(73.4 \%)$ & 73 & $(24 / 6 \%)$ & 297 & \multirow{2}{*}{$\begin{array}{c}\mathrm{X} 2=12.03 ; \\
\text { d.f. }=2 ; p=0.002\end{array}$} \\
\hline & Female & 7 & $(2.4 \%)$ & 212 & $(73.1 \%)$ & 71 & $(24.5 \%)$ & 290 & \\
\hline \multirow[t]{4}{*}{ Education } & Illiterate & 3 & $(2.4 \%)$ & 95 & $(76.0 \%)$ & 27 & $(21.6 \%)$ & 125 & \multirow{4}{*}{$\begin{array}{c}\mathrm{X} 2=52.44 ; \\
\text { d.f. }=6 ; \mathrm{P}<0.001 *\end{array}$} \\
\hline & Primary & 2 & $(1.3 \%)$ & 115 & $(76.2 \%)$ & 34 & $(22.5 \%)$ & 151 & \\
\hline & Secondary & 7 & $(2.6 \%)$ & 168 & $(72.4 \%)$ & 58 & $(25.0 \%)$ & 233 & \\
\hline & High & 1 & $(1.3 \%)$ & 52 & $(66.6 \%)$ & 25 & $(32.1 \%)$ & 78 & \\
\hline \multirow{4}{*}{$\begin{array}{l}\text { Duration of } \\
\text { hypertension } \\
\text { (years) }\end{array}$} & $<1$ & 5 & $(9.7 \%)$ & 33 & $(63.4 \%)$ & 14 & $(26.9 \%)$ & 52 & \multirow{4}{*}{$\begin{array}{c}\mathrm{X} 2=13.16 ; \\
\text { d.f. }=6 ; p=0.041 *\end{array}$} \\
\hline & $1-5$ & 4 & $(1.5 \%)$ & 227 & $(73.9 \%)$ & 76 & $(24.6 \%)$ & 307 & \\
\hline & $>5-10$ & 0 & $(0 \%)$ & 99 & $(75.0 \%)$ & 33 & $(25.0 \%)$ & 132 & \\
\hline & $>10$ & 4 & $(4.1 \%)$ & 71 & $(74.0 \%)$ & 21 & $(21.9 \%)$ & 96 & \\
\hline \multirow{2}{*}{$\begin{array}{l}\text { Family history } \\
\text { of hypertension }\end{array}$} & Positive & 8 & $(2.4 \%)$ & 272 & $(72.3 \%)$ & 95 & $(25.3 \%)$ & 375 & \multirow{2}{*}{$\begin{array}{c}\mathrm{X} 2=27.75 \\
\text { d.f. }=2 ; p<0.001 *\end{array}$} \\
\hline & Negative & 5 & $(2.8 \%)$ & 158 & $(74.1 \%)$ & 49 & $(23.1 \%)$ & 212 & \\
\hline
\end{tabular}

$\dagger$ Test of significance was done after re-categorization into $<1 \times 1-5 \mathrm{x}>5$

The senior citizens, the highly educated, those who had long duration of the disease and those with a positive family history of hypertension showed better knowledge than others. Many of the patients when being told that they have hypertension get scared and start to ask, read and gather information about the disease to promote their health and wellbeing on the long term. This is usually easier among the educated, and is accumulating with time (for senior citizens).

Regarding the practice; most of the patients showed fair level of practice and commitment to treatment and other measures, but this was not the case among the patients who had positive family history of hypertension, this might be due to that patients who have hypertensive family members may get exhausted with time, and frustrated from the long course treatment and care, and so, show less compliance.

In the current study; males showed better knowledge than females, may be because they can (from norms point of view) communicate more easily with the health workers, and enquire about their disease to gain more information, however, their attitude and practice scores were almost similar to those of the females.

The score of knowledge also showed a direct relation with the level of education, this was expected as higher education increases the awareness of the people regarding health issues, especially when it is related to their chronic illnesses.

The positive family history of hypertension also showed a significant relation with knowledge. The suffering of another member in the family usually urges the other members to learn more about the disease through taking care of their patient, and as a reflect to their fear from catching the disease in the future.

In respect with the attitude, more than $80 \%$ of the respondents showed good attitude. This finding agrees with other studies that revealed a high percentage (60$90 \%$ ) of hypertensive patients who reported good attitude. ${ }^{26,27}$
Generally the results revealed that the surveyed hypertensive patients have good knowledge and attitude about the disease but relatively poor practice. This might give an impression that the health education programs performed by the health authorities are insufficient and not fully successful. It might also be attributed to some reasons related to the patients themselves. Poor compliance to the treatment could be due to the high cost of drugs, adverse drug reactions, religious and cultural believes, and inadequate access to medical facilities and care. These reasons were comparable to a study conducted by the Busari et al. ${ }^{28}$

The interesting finding in the current study was that less than a quarter of the surveyed hypertensive patients reported full adherence to their medications prescribed by their doctors. This is in contrast to what was reported in $\mathrm{USA}^{29,30}(97 \%$ and $90 \%)$, and China $^{31}(88.9 \%)$.

The source of information in our sample was mainly health workers followed by relatives and friends, and the least was from printed materials such as medical journals and brochures, which is in line with other studies. ${ }^{29}$ However, Yasein et al. ${ }^{19}$ found that the main source of information was relatives and friends, and Megan $e t^{30}$ al who stated that the main source of information was medical journals and brochures.

\section{Limitations}

The major limitation of this study is the small size of the studied population and confined in a defined geographical area. For this reason, the findings should be generalized with caution.

\section{Conclusion}

It can be concluded from this study that the hypertensive patients in our community have relatively good knowledge and attitude, but had poor practice and compliance to treatment. This lack of awareness about hypertension had led the 
disease to be labelled as a silent killer. Sincere efforts are needed to increase the awareness through continuous group education courses in the primary health care centers and hospitals. Special health education and promotional programs through the media can play an important role in this aspect.

\section{Competing interest}

The authors declare that they have no competing interests.

\section{References}

1. Grove C, Laennec NJ. Disorders of the cardiovascular system. In: Kasper DL, Harrison TR, Editors. Harrison's principles of internal medicine. New York: McGraw-Hill, 2005.

2. World Health Report: Reducing risks, promoting healthy life. Geneva: World Health Organization. 2002.

3. Kearney PM, Whelton M, Reynolds K, Muntner $\mathrm{P}$, Whelton PK, He J. Global burden of hypertension. J. Hypertens 2004;22(1):140.

4. Bhatt DL, Steg PG, Ohman EM. International prevalence, recognition and treatment of cardiovascular risk factors in outpatients with athero-thrombosis; JAMA 2006;295(2):180-9.

5. Oliveria SA, Chen RS, McCarthy BD, Davis CC, Hill MN. Hypertension knowledge, awareness, and attitudes in a hypertensive population. J Gen Intern Med 2005;20(3):219-25.

6. Cheng S, Lichtman JH, Amatruda JM, Smith GL, Mattera JA, Roumanis SA, et al. Knowledge of blood pressure levels and targets in patients with coronary artery disease in the USA. J Hum Hypertens 2005;19(10):769-74.

7. Wang J, Staessen J, Franklin S, Fagard R, Gueyffier F. Systolic and diastolic blood pressure lowering as determinants of cardiovascular outcome. Hypertension 2005;45 (5):907-13.

8. Khosravi AR, Shirani SH, Shahrokhi SH, Mohammadifard N, Ansari R. Antihypertensive Drugs used by Hypertensive Patients In The Provincial Cities of Isfahan, Najafabad and Arak. ARYA J 2006;1(4):275-80.

9. Mokdad AH, Forouzanfar MH, Daoud F, et al. Health in Times of Uncertainty: a systematic analysis for the Global Burden of Disease Study 2013 in the Eastern Mediterranean Region, 19902013. Lancet Glob Health 2016;4(10): e704-13.

10. Gascon JJ, Sanchez-Ortuno M, Llor B, Skidmore D, Saturno PJ. Why hypertensive patients do not comply with the treatment: results from a qualitative study. Fam Pract 2004;21(2):125-30.

11. WHO. National Multiple indicator cluster survey (MICS), Baghdad: MOH Iraq, MOP Iraq \& WHO, 2016.

12. Ministry of Health. Statistical annual report of
Ministry of Health Iraq. Baghdad: Ministry of Health, 2015.

13. Al-Gasser N, Al-Alak M, Al-Shemeri A. Chronic non-communicable disease risk factors survey in Iraq. Baghdad: Ministry of Health/WHO, 2006.

14. Lafta RK, Hadi BJ, Shawki N. Systemic Hypertension in Type 2 Diabetes Mellitus. IJCM 2010;23(4):236-42.

15. Knight EL, Bohn RL, Wang PS, Glynn RJ, Mogun H, Avorn J. Predictors of uncontrolled hypertension in ambulatory patients. Hypertension 2001;38(4):809-14.

16. Bollu M, Nalluri KK, Prakash AS, Lohith MN, Venkataramarao N. Study of knowledge, attitude, and practice of general population of Guntur toward silent killer diseases: hypertension and diabetes. Asian J Pharm Clin Res 2015;8(4):74-8.

17. Mlunde L. Knowledge, Attitude and Practices towards Risk Factors for Hypertension in Kinondoni Municipality, Dar es Salaam. DMSJ 2007;14(2):59-62.

18. Kaur K, Sharma, Kaur G, Sharma D, Rai H. Practices of hypertensive patients visiting O.P.D at D.M.C \& H, Ludhiana. Nurs Midwifery Research J 2007;3(2):65-70

19. Yasein NA, Shakhatreh FM, Suleiman AA, Barghouti FF, Halaseh LJ, Abdulbaqi NK. Knowledge, Attitudes and Practices on Hypertension in patients attending Family Practice Clinics. Health MED 2011;5(6):1404-14.

20. Susan A, Roland S, Bruce D, Catherine, Martha N. Hypertension Knowledge, Awareness, and Attitudes in a Hypertensive Population. $J$ Gen Intern Med 2005;20(3):219-25.

21. Terry D, Pencina M, Vasan R, Murabito J. Cardiovascular risk factors predictive for survival and morbidity-free survival in the oldest -old Framingham Heart Study participants. $J$ Am Geriatr Soc. 2005;53(11):1944-50.

22. Sowielem LS. Compliance \& knowledge of hypertensive patients attending PHC centers in Al Khobar, Saudi Arabia. Eastern Mediterr Health J 1998;4(2):301-7.

23. Iyalomhe GBS and Iyalomhe SI. Hypertensionrelated knowledge, attitudes and life-style practices among hypertensive patients in a suburban Nigerian community. J Public Health Epidemiol 2010;2(4):71-7.

24. Anowie1 F and Darkwa S. The Knowledge, Attitudes and Lifestyle Practices of Hypertensive Patients in the Cape Coast Metropolis-Ghana. $J$ Scientific Res Rep 2015;8(7):1-15.

25. Shaikh MA, Yakta D, Kumar SR. Hypertension Knowledge, Attitude and Practice in Adult Hypertensive Patients at LUMHS. JLUMHS 2012;11(2):113-6. 
26. Jokisalo E, Kumpusalo E, Enlund H, Takala J. Patients' perceived problems with hypertension and attitudes towards medical treatment. Hum Hypertens 2001;15(11):755-61.

27. Kusuma YS, Gupta SK, Pandav CS. Knowledge and perceptions about hypertension among neo- and settled-migrants in Delhi, India. $C V D$ Prevention Control 2009;4(2):119-29.

28. Busari OA, Olanrewaju TO, Desalu OO. Impact of patients' knowledge, attitude and practices on hypertension on compliance with antihypertensive drugs in a resource-poor setting. TAF Prev Med Bull 2010;9(2):87-92.
29. Weir MR, Maibach EW, Bakris GL. Implications of a Healthy Lifestyle and Medication Analysis for Improving Hypertension Control. Arch Intern Med 2000;160(4):481-90.

30. Egan BM, Lackland DT, Cutler NE. Awareness, Knowledge, and Attitudes of Older Americans About High Blood Pressure, Implications for Health Care Policy, Education, and Research. Arch Intern Med 2003;163(6):681-7.

31. Zhang X, Zhu M, Dip HH, Hu J, Tang S, Zhong $\mathrm{T}$, Ming $\mathrm{X}$. Knowledge, awareness, behavior (KAB) and control of hypertension among urban elderly in Western China. Int J Cardiol 2009;137 (1):9-15. 